\title{
Safra Kesesi Duplikasyonu
}

\section{Gallbladder Duplication}

\section{Arda Işık ${ }^{1}$, Deniz Fırat ${ }^{1}$, Mehmet Soytürk ${ }^{2}$, Hüseyin Eken ${ }^{1}$, Orhan Çimen ${ }^{1}$, İsmail Demiryılmaz ${ }^{1}$, İsmayil Yılmaz ${ }^{1}$}

${ }^{1}$ Erzincan Üniversitesi Tıp Fakültesi Genel Cerrahi Anabilim Dalı, Erzincan, Türkiye

${ }^{2}$ Erzincan Üniversitesi Tıp Fakültesi Radyoloji Anabilim Dalı, Erzincan, Türkiye

\section{ÖZET}

Safra kesesi duplikasyonu embiryogenez sırasında oluşan nadir bir konjenital anomalidir. Dünyada bugüne kadar 210 vaka tanımlanmıştır. Kırk yaşında karın ağrısı şikayeti ile değerlendirilen hastanın yapılan hepatobiliyer USGde safra kesesi duplikasyonu tespit edildi. Laparoskopik kolesistektomi sonrası hastanın şikayetleri geriledi. Safra kesesinde duplikasyon, triplikasyon ve septalı safra kesesi olarak varyasyonlar olabilir. Preoperatif değerlendirilmesi, perioperatif komplikasyonlar açısından önemlidir.

Anahtar Sözcükler: Duplikasyon, konjenital anomali, safra kesesi

Geliş Tarihi: 30.07.2015

Kabul Tarihi: 30.04.2016

\begin{abstract}
Gallbladder duplication which occurs during embryogenesis is a rare congenital anomaly. Two hundred ten cases were defined in the world. Forty years old patient who had abdominal pain was evaulated. He had gallbladder duplication diagnosed by hepatobiliary ultrasonography. After laparoscopic cholecystectomy, his complaints diminished. There can be variations such as duplication, triplication and septate gallbladder. Preoperative evaulation is important for perioperative complications.
\end{abstract}

Key Words: Duplication, congenital anomaly, gallbladder

Received: 07.30.2015

Accepted: 04.30.2016

\section{GiRiş}

Safra kesesi duplikasyonu embriyogenez sırasında oluşan nadir bir konjenital anomalidir. Dünyada bugüne kadar 210 vaka tanımlanmıştır(1). Safra kesesi duplikasyonu asemptomatik olabileceği gibi kolelitiyazis olmasa dahi safra koliğine bağlı karın ağrısı şikayetine yol açabilmektedir. Ayırıcı tanıda safra kesesi divertikülü, safra kesesinde katlantı, Frigyalı şapkası, koledokal kist, perikolekistik sıvı, fokal adenomyomatozis ve intraperitoneal fibröz bantlar yer almaktadır. Safra kesesi ile ilgili hastalıklarda ultrasonografi(USG) görüntülemede tercih edilen ilk yöntem olup, sonografik görüntüleme yöntemi ile safra kesesi duplikasyonu tanısı koymak mümkündür (2).

\section{OLGU SUNUMU}

Kırk yaşında son 6 aydır yemeklerden sonra ara ara karın ağrısı şikayeti ile değerlendirilen erkek hastanın yapılan hepatobiliyer usgde kolelityasizin eşlik etmediği safra kesesi duplikasyonu tespit edildi (Resim 1). Yapılan üst gastrointestinal sistem endoskopisinde patoloji gözlenmedi. Kan biyokimya değerlerinde ve tam kan sayımında özellik yok idi. Öyküsünde geçirilmiş operasyon anamnezi ve hastalığı bulunmuyordu. Hastaya standard laparoskopik kolesistektomi operasyonu uygulandı. Operasyonda safra kesesi fundusun da fissür görünümü olan duplike hidropik safra kesesi izlendi (Resim 2). Laparoskopik kolesistektomi operasyonu sonrası 1. günde taburcu edildi. Postoperatif takiplerinde hastanın şikayetleri tamamen geriledi.

Çalışmamız 2015 HPB Cerrahisi Kongresinde sunulmuştur.

Yazışma Adresi / Address for Correspondence: Dr.Arda Işık Erzincan Üniversitesi Tıp Fakültesi Genel Cerrahi Anabilim Dalı Erzincan- Turkey E-posta: kararda@yahoo.com

(CTelif Hakkı 2016 Gazi Üniversitesi Tıp Fakültesi - Makale metnine http://medicaljournal.gazi.edu.tr/ web adresinden ulaşılabilir.

(C) Copyright 2016 by Gazi University Medical Faculty - Available on-line at web site http://medicaljournal.gazi.edu.tr/

doi:http://dx.doi.org/10.12996/gmj.2016.46 


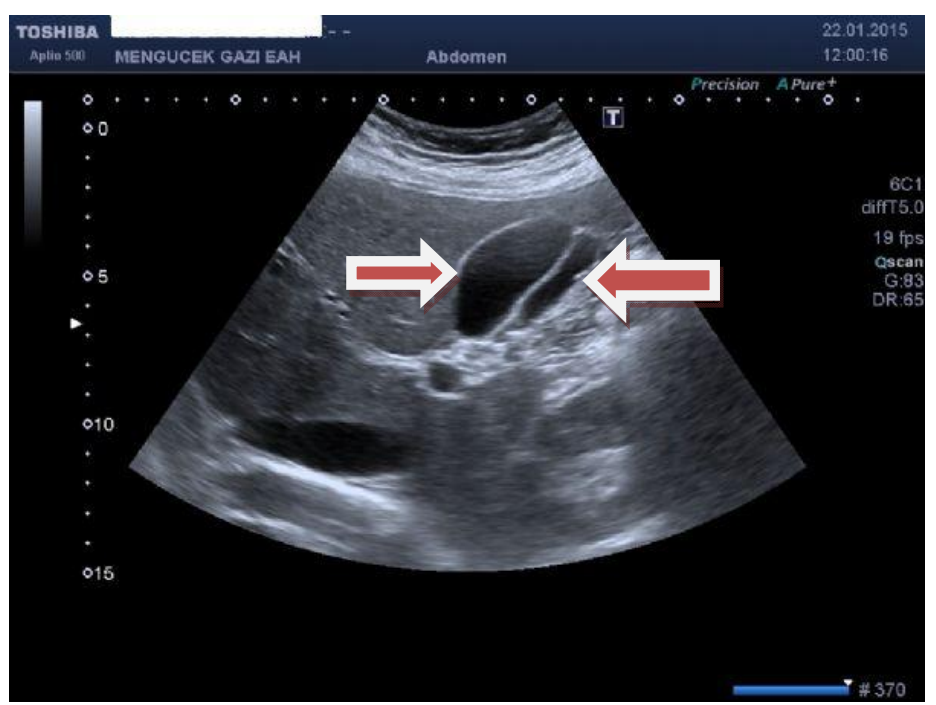

Resim 1: Safra kesesi duplikasyonu

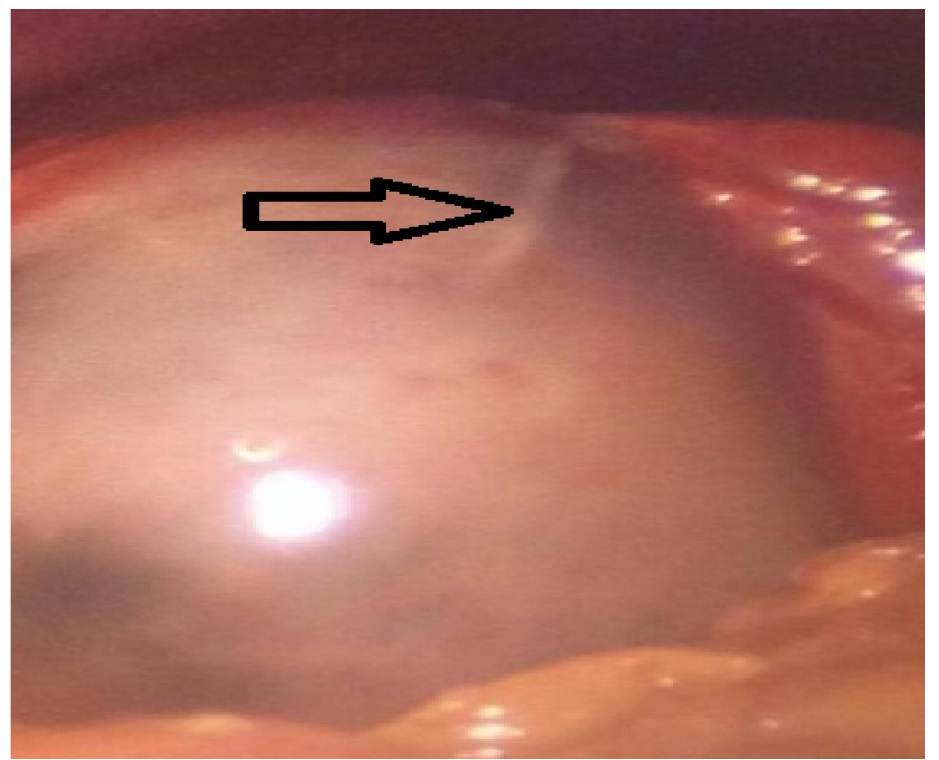

Resim 2: Fundusta fissür görünümü(ok) olan duplike safra kesesinin intraoperatif görüntüsü

\section{TARTIŞMA}

Safra yollarında anatomik varyasyon oranı \%60 oranında olup cerrahi komplikasyonların oluşumunun altta yatan ana sebeplerinden biridir. Safra kesesinde duplikasyon, triplikasyon ve septalı safra kesesi olarak varyasyonlar olabilir. Beraberinde çift sistik kanal ve çift sistik arter hatta koledok duplikasyonu gözlenebilir(3).

Sayı anomalileri üst başlığı altında yer alan safra kesesinin duplikasyon anomalileri kendi içerisinde iki tipe ayrılmaktadır. İlki safra kesesi fundus ve korpusunun longitüdinal bir septumla tam ya da parsiyel iki ayrı lümene bölündüğü, bölünen iki ayrı lümenin infundibulumda tekrar birleşerek tek bir sistik kanalla koledoğa açıldığı bilobe safra kesesi (vesica fellae divisa); ikincisi, iki ayrı fundus, korpus, infundibulum ve iki ayrı sistik kanalın bulunduğu, birbirinden tamamen ayrı çift safra kesesi (vesica fellae duplex)dir. Bilobe safra kesesi çok daha nadir görülen bir durumudur. Bizim olgumuzda da bilobe safra kesesi gözlendi. Bu anomalilerin taş oluşumu ve inflamasyona yol açtıkları da düşünülmektedir. Literatürde sonografik görüntülemenin, duplikasyonun tiplendirilmesinde yeterli olduğu bildirilmektedir. Ortak infundibuluma sahip duplikasyon olgularında luminal taşların pozisyona bağlı yer değiştirebildiği de bildirilmiştir(4). Tedavisi laparoskopik kolesistektomidir(5-6). Preoperatif değerlendirilmesi, perioperatif komplikasyonlar acısından önemlidir.

\section{Çıkar Çatışması}

Yazarlar herhangi bir çıkar çatışması bildirmemişlerdir.

\section{KAYNAKLAR}

1- Botsford A, McKay K, Hartery A, Hapgood C. MRCP imaging of duplicate gallbladder: a case report and review of the literature. Surg Radiol Anat. 2015 Mar 11.

2- Çelik MA,YildizZ K, Alhan E. Safra Kesesi Duplikasyonu Düzce Üniversitesi Sağlık Bilimleri Enstitüsü Dergisi 2015; 5: 50-51

3- Görkem SB, Doğanay $S$, Kahriman $G$, Küçükaydın $M$, Coşkun A. Acute cholecystitis of a duplicated gallbladder with double cystic duct in a 10 year old boy. Balkan Med J. 2014;31:366-7.

4- Gürses C,Kaya A,Yağcı A. Tanısal ve Girişimsel Radyoloji 2002 8:7678

5- Şahin Ş, Haktanır A, Safra Kesesi Duplikasyonu: Olgu Sunumu Kocatepe Tıp Dergisi 12: 70-73

6- Isık A, Demiryilmaz I, Yılmaz I, Fırat D, Cimen O, Eken H. Laparoskopik Apendektomide Manuel Düğümün Etkinliği Gazi Medical Journal 2015;27:19-20 